\title{
Effects of Hydrolysis on the Removal of Cured Urea- Formaldehyde Adhesive in Waste Medium-Density Fiberboard
}

\author{
By: \\ Muhammad Adly Rahandi Lubis ${ }^{1,4^{*}}$, Wahyu Hidayat ${ }^{2}$, Lukmanul Hakim Zaini ${ }^{3}$, Byung \\ Dae Park ${ }^{4}$ \\ ${ }^{1}$ Research Center for Biomaterials, Indonesian Institute of Sciences, Cibinong16911, West Java, Indonesia \\ ${ }^{2}$ Department of Forestry, Faculty of Agriculture, University of Lampung. Jl. Sumantri Brojonegoro 1, Bandar \\ Lampung, 35145, Lampung, Indonesia \\ ${ }^{3}$ Department of Forest Products, Faculty of Forestry, IPB University. Jl. Raya Dramaga, Bogor 16680, West \\ Java, Indonesia \\ ${ }^{4}$ Department of Wood and Paper Science, Kyungpook National University, Daegu, 41566, Republic of Korea \\ *E-mail: adlylubis89@gmail.com
}

\begin{abstract}
The vast production of medium-density fiberboard (MDF) in the world is expected to generate a large quantity of waste MDF after its service life, which requires the recycling of waste MDF $(w M D F)$. This work attempted to investigate the removal of cured urea-formaldehyde (UF) resins adhesive in $w M D F$ using hydrolysis for a possible way of recycling $w M D F$. The $w M D F s$ were fabricated with two kinds of recycled fibers ( $R F s)$ : refiner recycled fibers $(R R F s)$ and hammer mill recycled fibers (HRFs) from red and radiata pine. The $W M D F s$ were also produced at different RFs contents, such as 0, 5, 10, 20, 30, 50, and 100\%. The panels were then hydrolyzed with water and oxalic acid solution to remove the cured UF resins. The Kjeldahl method was applied to determine the nitrogen $(N)$ content in the panel before and after hydrolysis. Regardless of the wood species and recycling process, the mass loss, $\mathrm{pH}$, and formaldehyde liberation of $w M D F s$ after hydrolysis were greater for oxalic acid than those in water, confirming a greater $N$ content had been extracted by oxalic acid than water. The resin removal became greater as the RFs content increased. In addition, the resin removal was slightly greater in wMDFs made of HRFs than the RRFs. Moreover, red pine RFs gave higher resin removal than radiata pine. These results suggested that a proper combination of the recycling process and additives could make it possible to recycle $w M D F$ panels in the future.
\end{abstract}

Keywords: cured urea-formaldehyde, hydrolysis, medium-density fiberboard, oxalic acid, recycling

\section{INTRODUCTION}

Medium-density fiberboard (MDF) is developed during the 1960s using a process of gluing wood fibers with urea-formaldehyde (UF) resins under high temperature and pressure (Donaldson and Lomax 1989). MDF can be finished into a smooth surface and can be machined into a complicated and curved profiles, which eliminating the need of veneers and laminates. This makes MDF as one of the main wood-based composite product used for interior applications, such as furniture, moldings, and doors (Lubis et al. 2018b; Ormondroyd and Stefanowski 2015). It is estimated that MDF will become wood wastes after a life span of 15-20 years. As a result, waste MDF (wMDF) panels are usually sent to boilers or landfills in most of MDFs mills. Nevertheless, disposing of wMDF in landfills is no longer an acceptable solution because it consumes significant land space (Kharazipour and Kues 2007). In other cases, burning is also not an environmentally friendly solution as it releases dioxins, carbon dioxide, methane, 
and other pollutants that can harm the environment (Tatàno et al. 2009). Therefore, the recycling of wMDFs is more benign than burning or landfilling does (Morris 2017). However, recycling wMDF is difficult because high levels of UF resin adhesive hold strong bonds between the fibers (Grigsby et al. 2014a).

UF resins are classified as thermosetting polymer. It means that the cured UF resin adhesives are insoluble and infusible (Dunky 1998). Fortunately, the cured UF resins are susceptible to hydrolysis; thus, determining an optimum hydrolysis condition for removing cured UF resins in wMDF is necessary. The hydrolysis of cured UF resins depends on its chemical structure and cross-linking degree. The cured resins are more susceptible to hydrolysis under humid and acidic conditions than under neutral and alkaline conditions (Dutkiewicz 1983; Liu et al. 2018; Myers 1986). The removal of cured UF resins from MDF panels was considerably greater under acidic conditions than those under neutral and alkaline conditions (Lubis et al. 2018a). It was found that more than $74 \%$ of cured UF resins had been removed by hydrolysis at $80^{\circ} \mathrm{C}$ for $2 \mathrm{~h}$ using an oxalic acid solution $(1 \% \mathrm{w} / \mathrm{w})$. However, studies on the removal of cured UF resins in wMDF are limited. Therefore, this paper attempted to investigate the removal of cured UF resins in wMDF, by producing wMDF panels at different fiber contents and from different methods of preparing fibers. The wMDF panels were then hydrolyzed in both distilled water and oxalic acid at $80^{\circ} \mathrm{C}$ for $2 \mathrm{~h}$. Hydrolytic degradation behavior of cured UF resins, extracted nitrogen, and resin removal from wMDF was investigated in detail using several methods.

\section{MATERIALS AND METHODS}

\section{Materials}

The technical grade of oxalic acid (Daejung Chemical, Republic of Korea) was used to prepare $0.1 \mathrm{M}$ of solution. Distilled water prepared in the laboratory using reverse osmosis system (Upure RO Tech., DLS, Republic of Korea) was also used. Virgin fibers (VFs), UF resins (E1 grade, $60 \%$ solids content, $260 \mathrm{mPa} \cdot \mathrm{s}$ viscosity, $79 \mathrm{~s}$ gel time, and $\mathrm{pH} 9.3$ ), and emulsion wax (40\% solids content) were supplied from a commercial MDF mill (Hansol Home Deco, Iksan, Republic of Korea). $\mathrm{NH}_{4} \mathrm{Cl}$ solution $(20 \% \mathrm{w} / \mathrm{v})$ was used as a hardener. All recycled fibers (RFs) were obtained from the Korea Forest Research Institute (KFRI) (Seoul, Republic of Korea).

\section{Fibers Characterization}

A certain number of fibers were taped to microscope glass slides using double-sided tape and subsequently coated with platinum by ion sputtering E-1030 for $10 \mathrm{~min}$. The fibers were scanned triplicate using a scanning electron microscopy (SEM) (Hitachi SU 8220, Japan) coupled with an energy dispersive X-ray spectroscopy (EDS) (EMAX 6853-H, Horiba, UK) at $15 \mathrm{kV}$ with a $\mathrm{K} \alpha 1 \mathrm{X}$-ray source to examine the chemical element composition (Park et al. 2011, Singh et al. 2015).

\section{Preparation of Waste MDF}

Preparation of recycled fibers (RF) and waste MDF (wMDF) were done according to a published method (Lubis et al. 2018b). Briefly, RF were prepared from MDF panels made of red pine (Pinus densiflora Siebold \& Zucc.) and radiata pine (Pinus radiata D. Don). The panels were then cut into pieces of $30 \mathrm{~mm} \times 30 \mathrm{~mm} \times 25 \mathrm{~mm}$. These pieces were then steam-treated at $180^{\circ} \mathrm{C}$ and $600 \mathrm{kPa}$ pressure for $30 \mathrm{~min}$. Refining and hammer milling methods were employed to prepare RFs from the raw MDF panels; the RFs thus obtained were designated as refiner RFs (RRFs) and hammer mill RFs (HRFs), respectively. In wMDF manufacture, approximately 12\% 
UF resins and $1 \%$ of emulsion wax, based on the dry mass of the fibers, were prepared in 1000 $\mathrm{mL}$ of beaker glass. Furthermore, $3 \%$ of $\mathrm{NH}_{4} \mathrm{Cl}$ was added into the mixture based on UF resins solids content. The mixture then was sprayed onto the fibers in a drum-type mechanical blender with the RFs content of $0,5,10,20,30,50$, and $100 \%$. The UF resins and emulsion wax were fed into an atomization nozzle using a peristaltic pump at $50 \mathrm{RPM}$ and $196 \mathrm{kPa}$ of air pressure in the blender. The resinated fibers were used to form a fiber mat in a wooden forming box using an air blower. The mat was pre-pressed for $30 \mathrm{~s}$ and then hot-pressed at $180^{\circ} \mathrm{C}$ and $2.45 \mathrm{MPa}$ for 4 min to produce a $700 \mathrm{~kg} / \mathrm{m}^{3}$ wMDF panel $(300 \mathrm{~mm} \times 400 \mathrm{~mm})$. The final thickness was adjusted to $15 \mathrm{~mm}$ using two stop-bars in the hot press.

\section{Hydrolysis of Waste MDF Panels}

The wMDF panels were cut into 1-cm strips. These strips were then ground using a grinding mill (MF 10 basic; IKA Werke, Germany) to obtain wMDF powder samples having a size of about $1 \mathrm{~mm}$. Approximately $4 \mathrm{~g}$ of wMDF powder was added to a 500-mL beaker glass. Subsequently, $400 \mathrm{~mL}$ of hydrolysis solutions were added to the beaker. The mixture was then hydrolyzed on a hot-plate with continuous stirring at $80^{\circ} \mathrm{C}$ for $2 \mathrm{~h}$ (Lubis et al. 2018a). After hydrolysis, the sample was filtered using a filter paper (Whatman No. 1, Ø: $90 \mathrm{~mm}$ ) under vacuum using an aspirator system to obtain the solid residue and extract solution. Hydrolysis of wMDF was done with one replication. The solid residue was subsequently dried in an oven at $105^{\circ} \mathrm{C}$ for $3 \mathrm{~h}$. The mass loss of the sample was calculated by weighing the sample before and after the hydrolysis to obtain its initial and final weights (Park and Jeong 2011). The acidity of extract solution was determined using a digital $\mathrm{pH}$ meter with one replication. The formaldehyde liberation of wMDF in extract solution was determined using a TAPPI standard method with one replication (TAPPI 2001). The Kjeldahl nitrogen method was used to determine the nitrogen (N) content of wMDF before and after the hydrolysis according to the procedure of a TAPPI standard method with one replication (TAPPI 1997). The extracted nitrogen and resin removal were then calculated using several equations as reported in the published works (Grigsby et al. 2014a, b; Lubis et al. 2018a, b).

\section{RESULTS AND DISCUSSION}

\section{Characteristics of MDF Fibers}

Chemical compositions of all fibers are presented in Table 1. The SEM-EDS analysis showed that all recycled fibers (RF) contained a higher amount of carbon $(\mathrm{C})$ and nitrogen $(\mathrm{N})$ compared to the virgin fibers (VF). However, the RFs had less amount of oxygen (O) than those of VFs. This implies that recycling processes have damaged some of wood components. According to the result, both radiata and red pine HRFs had higher $\mathrm{N}$ content than red pine RRFs. This could be due to the refining process that removed more UF resins in the RFs than those of the hammer milling did. Hammer milling was known as a mechanical process (Wan et al. 2014), while refining was a thermomechanical process (Roffael et al. 2016). Presumably, the latter has a significant effect on the removal of UF resins from the RFs, although all fibers are pre-treated at the same condition. Moreover, the high content of $\mathrm{C}$ and $\mathrm{N}$ in the RFs is likely originated from the UF resins as adhesives, which comprises of $\mathrm{C}$ and $\mathrm{N}$ (Lubis et al. 2018a). 
Table 1. Chemical compositions of MDF fibers examined by SEM-EDS analysis

\begin{tabular}{lccc}
\hline \multirow{2}{*}{ Type of MDF fiber } & $\mathrm{C}$ & $\mathrm{O}$ & $\mathrm{N}$ \\
\cline { 2 - 4 } & $56.2 \pm 0.54$ & $43.8 \pm 0.53$ & $0.0 \pm 0.00$ \\
\hline Red pine VFs & $57.6 \pm 0.36$ & $39.7 \pm 0.26$ & $2.5 \pm 0.55$ \\
Red pine RRFs & $62.4 \pm 4.65$ & $33.1 \pm 3.58$ & $4.3 \pm 1.80$ \\
Radiata pine HRFs & $66.7 \pm 3.42$ & $25.9 \pm 3.31$ & $7.3 \pm 0.49$ \\
Red pine HRFs & & & \\
\hline
\end{tabular}

\section{Hydrolysis of Waste MDF Panels}

Different hydrolytic degradation behaviors of wMDF panels, such as mass loss, $\mathrm{pH}$, and formaldehyde liberation are displayed in Figures 1 and 2. Based on the results, the mass loss of red pine RRFs was higher than those of both radiata and red pine HRFs. It seems the mass loss not only comes from cured UF resins but also from wood components. This is probably caused by refining process, which produces relatively short fibers under applied high-temperature steam and pressure (Roffael et al. 2016). Therefore, the higher proportion of fine fibers contributes to higher mass loss of RRFs than those of HRFs. On the contrary, the $\mathrm{pH}$ and formaldehyde liberation of wMDF panels showed an opposite trend to the mass loss. Both radiata and red pine HRFs had higher $\mathrm{pH}$ and formaldehyde liberation in the extract solution than that of red pine RRFs. This indicates both HRFs release more cured UF resins after hydrolysis. The $\mathrm{pH}$ increase is due to the formation of free $\mathrm{NH}_{3}$ from the degradation of cured UF resins, which leads to the formation of $\mathrm{NH}_{4} \mathrm{OH}$ in the solutions and increasing the $\mathrm{pH}$ of extract solution (Roffael et al. 2016; Wan et al. 2014).

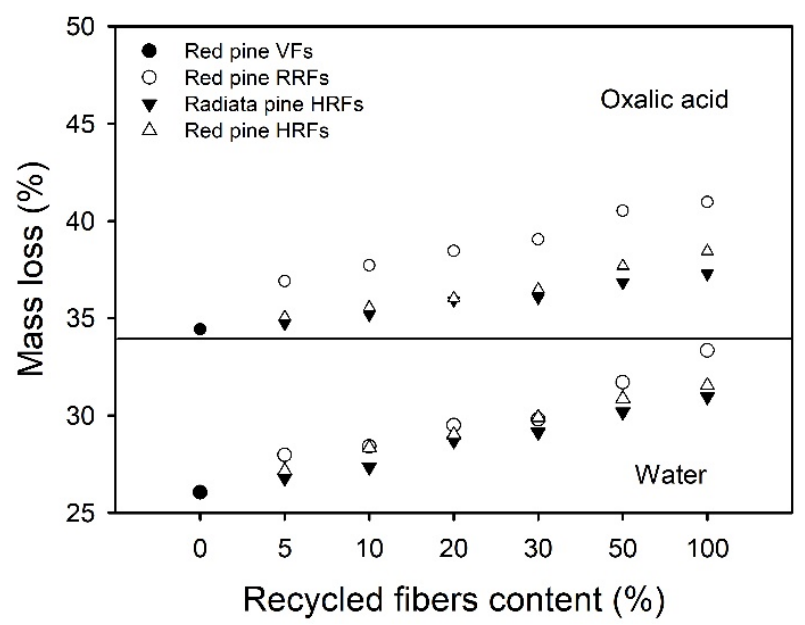

Figure 1. Mass loss of wMDF panels with different recycled fibers contents after hydrolysis in water and oxalic acid at $80^{\circ} \mathrm{C}$ for $2 \mathrm{~h}$.

Regardless of wood species and recycling process, mass loss, $\mathrm{pH}$, and formaldehyde liberation of wMDF were greater for oxalic acid than in water. The acid condition provides more $\mathrm{H}^{+}$and acts as nucleophiles for hydrolyzing the typical urea linkages (Hutchby 2013); hence the methylene ether linkage, N-methylene linkage, and amide linkage of cured UF resins in wMDF panels probably have been hydrolyzed greatly in oxalic acid. The mass loss, $\mathrm{pH}$, and formaldehyde liberation of wMDF panels were also getting higher by increasing the RFs content, indicating a higher amount of cured UF resins in wMDF panels had been removed by hydrolysis in oxalic acid than those in water. The higher mass loss, $\mathrm{pH}$, and formaldehyde liberation of 
wMDF panel made of $100 \%$ RFs implies that the presence of cured resins in RFs prevents those fibers for bonding with the fresh UF resins and eventually increases all parameters.
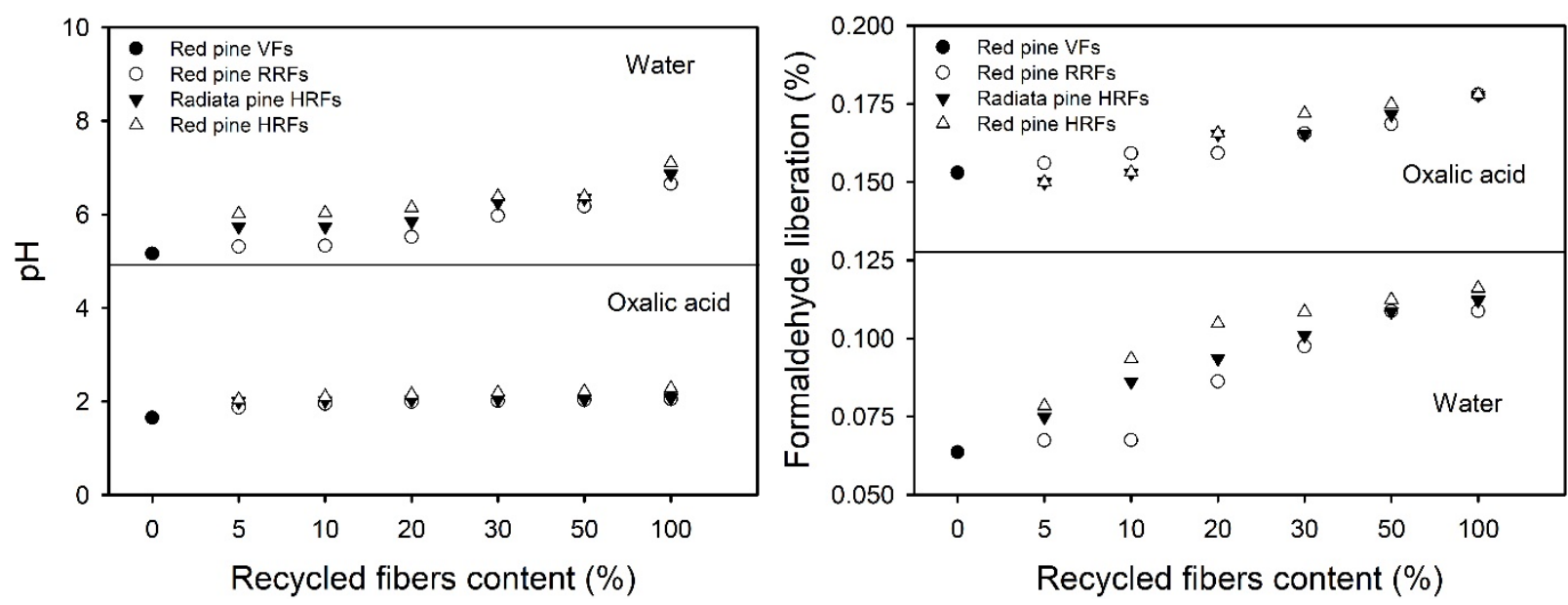

Figure 2. The $\mathrm{pH}$ (a) and formaldehyde liberation in extract solutions (b) from wMDF panels with different recycled fibers contents after hydrolysis in water and oxalic acid at $80^{\circ} \mathrm{C}$ for $2 \mathrm{~h}$.

\section{Removal of Cured UF Resins from Waste MDF}

The $\mathrm{N}$ content in rMDF panels before and after the hydrolysis was examined to understand the removal of cured UF resins from the panel. The N content of rMDF increased with an increase in the RFs content (Tables 2 and 3), regardless of the wood species and recycling process. This is likely due to the RFs already contain $\mathrm{N}$, and thus utilizing RF as a raw material in rMDF results in higher $\mathrm{N}$ content of the panels. The $\mathrm{N}$ content of rMDF panels was also getting higher by increasing the RFs content, which was in agreement with published works (Grigsby et al. 2014a; b, 2015).

Table 2. The $\mathrm{N}$ balance of wMDF panels with different fibers contents after hydrolysis in water at $80^{\circ} \mathrm{C}$ for $2 \mathrm{~h}$.

\begin{tabular}{lcccccc}
\hline \multirow{2}{*}{ Type of wMDF } & \multicolumn{7}{c}{ Recycled fibers content (\%) } \\
\cline { 2 - 7 } & $\mathbf{5}$ & $\mathbf{1 0}$ & $\mathbf{2 0}$ & $\mathbf{3 0}$ & $\mathbf{5 0}$ & $\mathbf{1 0 0}$ \\
\hline Red pine RRF: & & & & & & \\
- N in panel (\%) & 3.1 & 3.3 & 3.4 & 3.5 & 3.7 & 4.0 \\
- N in solid residues (\%) & 1.4 & 1.5 & 1.5 & 1.5 & 1.6 & 1.7 \\
- N in extract solutions (\%) & 1.6 & 1.7 & 1.8 & 1.8 & 2.0 & 2.2 \\
- Difference (\%) & 0.2 & 0.1 & 0.1 & 0.1 & 0.1 & 0.1 \\
\hline Radiata pine HRF: & & & & & & \\
- N in panel (\%) & 3.1 & 3.9 & 4.0 & 4.1 & 4.3 & 4.6 \\
- N in solid residues (\%) & 1.5 & 1.8 & 1.8 & 1.8 & 1.9 & 2.0 \\
- N in extract solutions (\%) & 1.5 & 1.9 & 2.1 & 2.1 & 2.2 & 2.2 \\
- Difference (\%) & 0.1 & 0.2 & 0.2 & 0.1 & 0.2 & 0.2 \\
\hline Red pine HRF: & & & & & & \\
- N in panel (\%) & 4.3 & 4.4 & 4.5 & 4.5 & 4.9 & 5.3 \\
- N in solid residues (\%) & 1.8 & 1.8 & 1.8 & 1.8 & 2.0 & 2.0 \\
- N in extract solutions (\%) & 2.1 & 2.2 & 2.3 & 2.4 & 2.6 & 2.9 \\
- Difference (\%) & 0.5 & 0.4 & 0.3 & 0.3 & 0.4 & 0.4 \\
\hline
\end{tabular}


As shown in Tables 2 and 3, the $\mathrm{N}$ content in solid residues of all wMDF panels after the hydrolysis in water are higher than those in oxalic acid. This indicates that higher $\mathrm{N}$ content are obtained in extract solutions after the oxalic acid hydrolysis than those of water. Around 1.5$2.9 \%$ of $\mathrm{N}$ was found in the extract solution after the hydrolysis in water, but $2.6-5.0 \%$ of $\mathrm{N}$ was found in the extract solution after hydrolysis in oxalic acid. This confirms that a greater amount of $\mathrm{N}$ has been extracted by oxalic acid than water. A study reported that oxalic acid extracted more $\mathrm{N}$ from MDF panels than that of water (Lubis et al. 2018a).

Among the wood species, red pine RFs has the higher $\mathrm{N}$ content in both solid residues and extract solutions than that of radiata pine RFs. This is due to the original $\mathrm{N}$ content of red pine is higher than that of radiata pine (Table 1), therefore resulting in higher $\mathrm{N}$ content in both solid residues and extract solutions. In comparing the recycling process, the hammer milling process results in higher $\mathrm{N}$ content in the panels than those of refining, thus resulting in a greater amount of $\mathrm{N}$ thas has been extracted from the panels.

Furthermore, regardless of the wood species and recycling process, hydrolysis of wMDF panels in water gives around 53-62\% of extracted N. Meanwhile, around 93-98\% of $\mathrm{N}$ had been extracted by hydrolysis in oxalic acid solution (Figure 3a). The amount of $\mathrm{N}$ had been extracted from the panel by hydrolysis is getting higher as the RFs content increase. This implies that utilizing RFs as raw material for wMDF panels may prevent inter-fiber bonding due to the presence of cured UF resins. Therefore, a higher amount of N-containing cured UF resins can be extracted from the wMDF panel by hydrolysis. However, the extracted $\mathrm{N}$ from the panel not only comes from cured UF resins but also from the fibers. Several studies reported that virgin fibers contained $0.1-0.5 \%$ of $\mathrm{N}$ (Cowling and Merrill 1966; Lubis et al. 2018a).

Table 3. The $\mathrm{N}$ balance of wMDF panels with different recycled fibers contents after hydrolysis in oxalic acid at $80^{\circ} \mathrm{C}$ for $2 \mathrm{~h}$.

\begin{tabular}{lcccccc}
\hline \multirow{2}{*}{ Type of wMDF } & \multicolumn{7}{c}{ Recycled fibers content (\%) } \\
\cline { 2 - 7 } & $\mathbf{5}$ & $\mathbf{1 0}$ & $\mathbf{2 0}$ & $\mathbf{3 0}$ & $\mathbf{5 0}$ & $\mathbf{1 0 0}$ \\
\hline Red pine RRF: & & & & & & \\
- N in panel (\%) & 3.1 & 3.3 & 3.4 & 3.5 & 3.7 & 4.0 \\
- N in solid residues (\%) & 0.1 & 0.1 & 0.1 & 0.1 & 0.1 & 0.1 \\
- N in extract solutions (\%) & 2.6 & 2.8 & 3.1 & 3.1 & 3.4 & 3.8 \\
- Difference (\%) & 0.4 & 0.4 & 0.3 & 0.2 & 0.2 & 0.2 \\
\hline Radiata pine HRF: & & & & & & \\
- N in panel (\%) & 3.1 & 3.9 & 4.0 & 4.1 & 4.3 & 4.6 \\
- N in solid residues (\%) & 0.1 & 0.1 & 0.1 & 0.1 & 0.1 & 0.1 \\
- N in extract solutions (\%) & 2.7 & 3.4 & 3.6 & 3.7 & 4.0 & 4.4 \\
- Difference (\%) & 0.3 & 0.4 & 0.3 & 0.2 & 0.2 & 0.1 \\
\hline Red pine HRF: & & & & & & \\
- N in panel (\%) & 4.3 & 4.4 & 4.5 & 4.5 & 4.9 & 5.3 \\
- N in solid residues (\%) & 0.2 & 0.2 & 0.2 & 0.2 & 0.2 & 0.2 \\
- N in extract solutions (\%) & 3.8 & 4.0 & 4.1 & 4.1 & 4.6 & 5.0 \\
- Difference (\%) & 0.3 & 0.3 & 0.2 & 0.2 & 0.1 & 0.1 \\
\hline
\end{tabular}

After calculating the resin removal using several equations as reported in published works (Grigsby et al. 2014b; a, 2015), it was found that the removal of cured UF resins from wMDF was higher in oxalic acid than the water. The hydrolysis in water removed around $48-56 \%$ of cured UF resins from wMDF, meanwhile about $74-95 \%$ of cured resins had been removed by hydrolysis in oxalic acid (Figure 3b). The proportionally increases trend was also found in resin removal, where the amount of resin had been removed by hydrolysis is getting higher as the RFs content increase. A remarkable amount of cured UF resins had been removed by hydrolysis at 
$100 \%$ RFs content indicated that the presence of cured resins in RFs prevented those fibers for bonding with the fresh UF resins; thus, resulting in highest resin removal.
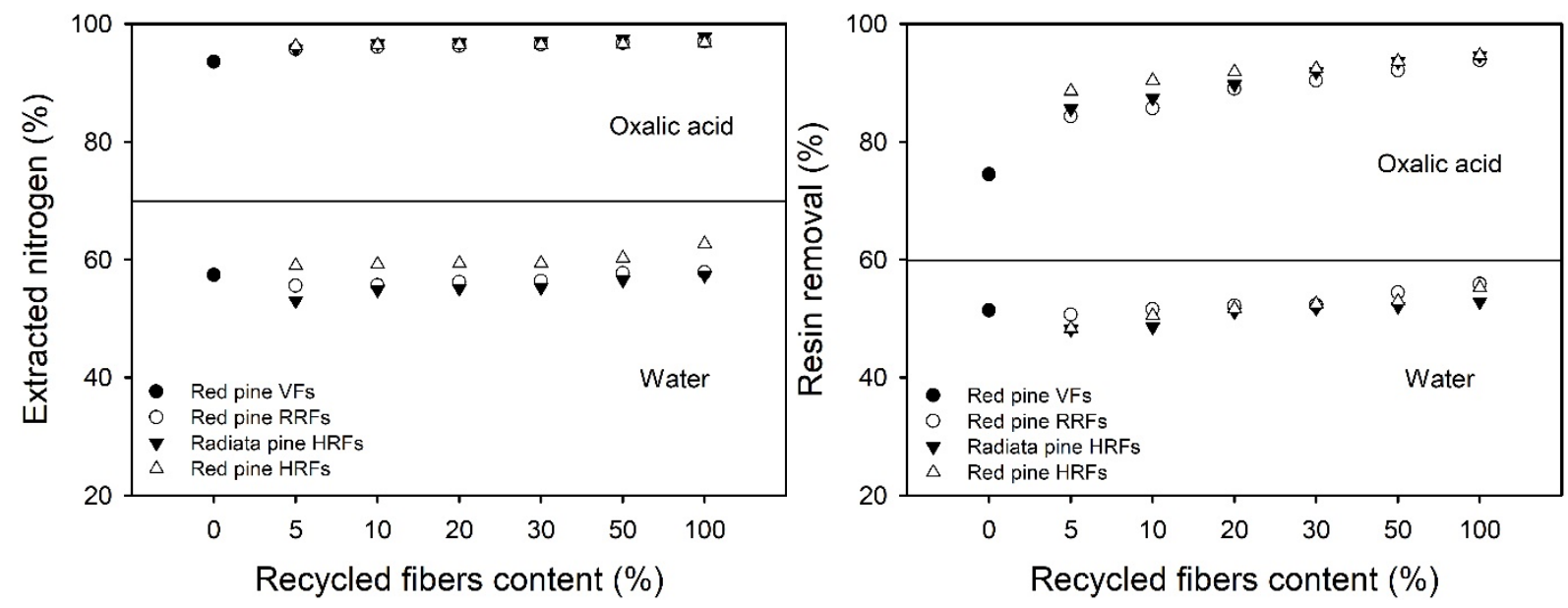

Figure 3. Extracted nitrogen (a) and resin removal (b) from wMDF panels with different recycled fibers contents after hydrolysis in water and oxalic acid at $80^{\circ} \mathrm{C}$ for $2 \mathrm{~h}$.

\section{CONCLUSIONS}

Higher mass loss, formaldehyde liberation, and $\mathrm{pH}$ suggested that a greater amount of cured UF resins had been removed from wMDF panels by hydrolysis. It was found that oxalic acid removed a greater amount of cured UF resins than those of water. The resin removal from wMDF panels depended on the RFs content, type of recycling process, and hydrolysis additives. The resin removal became greater as the RFs content increased. In addition, the resin removal was slightly greater in wMDF made of HRFs than the RRFs. Moreover, red pine RFs gave higher resin removal than that of radiata pine. This study found that the highest resin removal was obtained from the wMDF panel made of red pine HRFs. The best hydrolysis condition was found in oxalic acid at $80^{\circ} \mathrm{C}$ for $2 \mathrm{~h}$. The proper combination of recycled fibers, methods of preparing recycled fibers, and hydrolysis conditions could give a possible way to recycle wMDF panels in the future.

\section{REFERENCES}

Cowling, E. B., and Merrill, W. 1966. Nitrogen in Wood and Its Role in Wood Deterioration. Canadian Journal of Botany 44(11): 1539-1554. DOI: 10.1139/b66-167

Donaldson, L. A., and Lomax, T. Da. 1989. Adhesive/Fibre Interaction in Medium Density Fibreboard. Wood Science and Technology 23(4): 371-380. DOI: 10.1007/BF00353254

Dunky, M. 1998. Urea-Formaldehyde (UF) Adhesive Resins for Wood. International Journal of Adhesion and Adhesives 18(2): 95-107. DOI: 10.1016/S0143-7496(97)00054-7

Dutkiewicz, J. 1983. Hydrolytic Degradation of Cured Urea-Formaldehyde. Journal of Applied Polymer Science 28(11): 3313-3320.

Grigsby, W. J., Carpenter, J. E. P., and Sargent, R. 2014a. Investigating the Extent of Urea Formaldehyde Resin Cure in Medium Density Fiberboard: Resin Extractability and Fiber Effects. Journal of Wood Chemistry and Technology 34(3): 225-238. DOI: 10.1080/02773813.2013.861850

Grigsby, W. J., Carpenter, J. E. P., Thumm, A., Sargent, R., and Hati, N. 2015. Labile Extractable 
Urea-Formaldehyde Resin Components from Medium-Density Fiberboard. Forest Products Journal 65(1-2): 15-19. DOI: 10.13073/FPJ-D-14-00030

Grigsby, W. J., Thumm, A., Carpenter, J. E. P., and Hati, N. 2014b. Investigating the Extent of Urea Formaldehyde Resin Cure in Medium Density Fibreboard: Characterisation of Extractable Resin Components. International Journal of Adhesion and Adhesives 50: 5056. DOI: 10.1016/j.ijadhadh.2013.12.020

Hutchby, M. 2013. Novel Synthetic Chemistry of Ureas and Amides. Springer-Verlag. DOI: 10.1017/CBO9781107415324.004

Jada, S. S. 1988. The Structure of Urea-Formaldehyde Resins. Journal of Applied Polymer Science 35(6): 1573-1592. DOI: 10.1002/app.1988.070350614

Kharazipour, A., and Kues, U. 2007. Recycling of Wood Composites and Solid Wood Products. in: Wood Production, Wood technology, and Biotechnological Impacts U. Kües, ed. Universitätsverlag Göttingen, Göttingen 509-533.

Liu, M., Wang, Y., Wu, Y., and Wan, H. 2018. Hydrolysis and Recycling of Urea Formaldehyde Resin Residues. Journal of Hazardous Materials 355: 96-103. DOI: 10.1016/j.jhazmat.2018.05.019

Lubis, M. A. R., Hong, M. K., and Park, B. D. 2018a. Hydrolytic Removal of Cured UreaFormaldehyde Resins in Medium-Density Fiberboard for Recycling. Journal of Wood Chemistry and Technology 38(1): 1-14. DOI: 10.1080/02773813.2017.1316741

Lubis, M. A. R., Hong, M. K., Park, B. D., and Lee, S. M. 2018b. Effects of Recycled Fiber Content on the Properties of Medium Density Fiberboard. European Journal of Wood and Wood Products 76(5): 1515-1526. DOI: 10.1007/s00107-018-1326-8

Lubis, M. A. R., and Park, B. D. 2018. Analysis of the Hydrolysates from Cured and Uncured Urea-Formaldehyde (UF) Resins with Two F/U Mole Ratios. Holzforschung 72(9): 759768. DOI: $10.1515 / \mathrm{hf}-2018-0010$

Morris, J. 2017. Recycle, Bury, or Burn Wood Waste Biomass?: LCA Answer Depends on Carbon Accounting, Emissions Controls, Displaced Fuels, and Impact Costs. Journal of Industrial Ecology 21(4): 844-856. DOI: 10.1111/jiec.12469

Müller, G., Schöpper, C., Vos, H., Kharazipour, A., and Polle, A. 2009. FTIR-ATR Spectroscopic Analyses of Changes in Wood Properties During Particle- and Fiberboard Production of Hard- and Softwood Trees. BioResources 4(1): 49-71. DOI: 10.15376/biores.4.1.49-71

Myers, G. E. 1986. Resin Hydrolysis and Mechanisms of Formaldehyde Release from Bonded Wood Products. in: Wood Adhesives in 1985: Status \& Needs A. W. Christiansen, ed. Forest Products Laboratory, Wisconsin 119-156.

Ormondroyd, G. A., and Stefanowski, B. 2015. Fibreboards and Their Applications. Wood Composites Elsevier. DOI: 10.1016/B978-1-78242-454-3.00005-6

Park, B. D., and Jeong, H. W. 2011. Hydrolytic Stability and Crystallinity of Cured UreaFormaldehyde Resin Adhesives with Different Formaldehyde/Urea Mole Ratios. International Journal of Adhesion and Adhesives 31(6): 524-529. DOI: 10.1016/j.ijadhadh.2011.05.001

Pizzi, A., and Mittal, K. 2003. Handbook of Adhesive Technology, Revised and Expanded. Handbook of Adhesive Technology, Revised and Expanded CRC Press. DOI: 10.1201/9780203912225

Roffael, E., Behn, C., Schneider, T., and Krug, D. 2016. Bonding of Recycled Fibres with UreaFormaldehyde Resins. International Wood Products Journal 7(1): 36-45. DOI: 10.1080/20426445.2015.1131918

TAPPI. 1997. Fiber Length of Pulp by Classification, Test Method T $233 \mathrm{~cm}-95$. Technical Association of the Pulp and Paper Industry, United States.

TAPPI. 2001. Analysis of Formaldehyde in Aqueous Solutions and of Free Formaldehyde in 
Resins, Test Method T 600 om-15. Technical Association of the Pulp and Paper Industry (TAPPI). United States.

Tatàno, F., Barbadoro, L., Mangani, G., Pretelli, S., Tombari, L., and Mangani, F. 2009. Furniture Wood Wastes: Experimental Property Characterisation and Burning Tests. Waste Management 29(10): 2656-2665. DOI: 10.1016/j.wasman.2009.06.012

Wan, H., Wang, X. M., Barry, A., and Shen, J. 2014. Recycling Wood Composite Panels: Characterizing Recycled Materials. BioResources 9(4): 7554-7565. DOI: 10.15376/biores.9.4.7554-7565

Wilcox, K. E. 2014. Using Regression Analyses for the Determination of Protein Structure from FTIR Spectra. Thesis. University of Manchester. 